\title{
A quantitative study exploring undergraduate nursing students' perception of their critical thinking and clinical decision making ability while using apps at the point of care
}

\author{
Monique G. Sedgwick ${ }^{* 1}$, Olu Awosoga ${ }^{1}$, Lance Grigg ${ }^{2}$, Jenna-Marie Durnin ${ }^{2}$ \\ ${ }^{1}$ Faculty of Health Sciences, University of Lethbridge, Lethbridge, Alberta, Canada \\ ${ }^{2}$ Faculty of Education, University of Lethbridge, Lethbridge, Alberta, Canada
}

Received: March 4, 2016

DOI: $10.5430 /$ jnep.v6n10p1
Accepted: March 30, 2016

Online Published: May 23, 2016

URL: http://dx.doi.org/10.5430/jnep.v6n10p1

\begin{abstract}
The purpose of this study was to explore how a smartphone app influences undergraduate nursing students' perceptions of their critical thinking and clinical decision making ability at the point of care. Using a pretest-posttest approach, the findings suggest that there were no statistically significant differences in the participants' perception of their critical thinking and clinical decision making ability over time. Statistically significant findings on four questionnaire items pertaining to participants' perception in their ability to engage in evidence based practice over time suggests that experience with the app, led the participants to believe the app provided them with the information they needed in order to engage in evidence based practice. Consequently, they were less likely to seek information from other sources. Although having learning resources available in clinical practice environments might enhance critical thinking ability, perhaps counterintuitively, the findings in this study suggest that having access to a clinical mobile app did not positively influence the participants' perceived critical thinking ability. Nurse educators therefore, must teach students how to be active learners as well as role model the proper use of critical thinking skills. Students need to be reminded to use institutional policies and procedure manuals as well as other appropriate sources of information. Last, students need to see registered nurses use critical thinking and clinical decision making dispositions by asking comprehensive questions, exploring assumptions and inferences, and incorporating varying resources into their decisions.
\end{abstract}

Key Words: Undergraduate nursing students, Preceptorship, Mobile technologies, Critical thinking, Clinical decision making

\section{INTRODUCTION}

A major goal of baccalaureate nursing education is the development and implementation of critical thinking in students. Consequently, the senior preceptored clinical experience is focused on helping students acquire the requisite knowledge and skills newly graduated nurses need to demonstrate on a regular basis. Hence, those skills basic to critical thinking and clinical decision-making feature prominently in the senior preceptorship. Now more than ever, in order to cope with a rapidly expanding nursing knowledge base, advances in science and technology, and the economic constraints within healthcare settings, nursing students need to be deft

\footnotetext{
*Correspondence: Monique G. Sedgwick; Email: monique.sedgwick@uleth.ca; Address: 4401 University Drive, Markin Hall, University of Lethbridge, Lethbridge, AB, Canada.
} 
critical thinkers.

Set against the back-drop of technocentric healthcare industries, hand-held technology has emerged as an effective clinical tool that supports evidence-based practice and the complex thinking necessary for sound clinical-decision making at the point of care. ${ }^{[1,2]}$ In particular, smartphones (devices that have advanced mobile communication and portable computation capabilities) are increasingly being used by clinicians, with up to $87 \%$ of healthcare professionals using them during clinical practice for data management and accessibility. ${ }^{[3-5]}$ Concomitant with the adoption of smartphones has been the development of a wide variety of software applications (programs that run on a mobile device to accomplish a specific purpose) for healthcare professionals. ${ }^{[6]}$ A specific purpose of many medical mobile applications (apps) is to support clinical decision-making. For example based on their functionality, some apps provide quick easy access to evidence-based information pertaining to clinical algorithms helping clinicians understand and apply principles of disease diagnosis. Other apps help clinicians to identify appropriate laboratory and radiology tests based on patient symptoms, provide access to drug references and medical calculators. ${ }^{[6]}$ The purpose of this study was to explore the impact of a smartphone application on undergraduate nursing students' critical thinking and clinical decision-making ability at the point of care during a senior preceptored clinical experience. The study is highly relevant as it explores critical thinking capacities in nursing students in their last practicum before entering the profession.

\subsection{Critical thinking definition}

Over the last number of decades, nurse educators have valued critical thinking as an important skill for nurses. ${ }^{\text {[7] }}$ Recently, as part of critical inquiry, critical thinking was identified as an entry-to-practice competency for registered nurses. ${ }^{\left[{ }^{8]}\right.}$ While few would argue that critical thinking is a valuable skill set registered nurses ought to possess, a literature review failed to produce an agreed upon definition of critical thinking in nursing or nursing education. ${ }^{[9,10]}$ That being said, while the criteria for being a critical thinker seems to be changing, ${ }^{\text {[11] }}$ the following criteria are frequently associated with a common set of skills and attitudes basic to critical thinking: i) gathering and seeking information; ii) questioning and investigating; iii) analyzing, evaluating, reassembling disparate pieces of data and making inferences; iv) problem solving including determining the appropriate way to treat the problem and application of theory; v) consulting with other healthcare team members and, vi) recognizing that patients with the same medical diagnosis may respond differently to the treatment modalities of that diagnosis. ${ }^{[12,13]}$

\subsection{Theoretical framework}

For this study, critical thinking was conceptualized as the students' intention to engage in an evaluative process based on a set of skills that results in justifiable decisions to be applied for the purpose of promoting human change. ${ }^{[14]}$ Clinical decision making was defined as those thinking strategies used to gather and analyze patient information, evaluate the significance of this information and weigh alternative courses of action. Clinical decision making was also considered to be context-dependent and domain-specific, incorporating knowledge unique to nursing within a specific practice setting. ${ }^{[14]}$

Critical thinking and clinical decision making are linked in so far that critical thinking is considered to be a necessary but not sufficient feature of the clinical decision making process. As others have argued, there appears to be a significant relationship between critical thinking and quality clinical decision making. ${ }^{[15]}$ In short, the skills, tools and attitudes basic to critical thinking are necessary, although not sufficient, if a nurse wants to make the best decision possible in any given nursing context. They are not sufficient because only the context can provide the information to be critically reflected upon. Hence, one can see why critical thinking skills and dispositions are considered to be requisite for the operationalization of evidence-based practice. ${ }^{[16]}$

\subsection{Literature review}

\subsubsection{Mobile technologies}

The use of handheld devices by nurses is largely a grassroots one. As a result, it lags behind physicians in uptake. ${ }^{[1]}$ That said, handheld devices are rapidly becoming an integral part of nursing practice. ${ }^{[18]}$ For example, nurse practitioner students in family and pediatric clinics found that using mobile technologies enhanced knowledge acquisition and supported cooperative learning. ${ }^{[19]}$ Furthermore, nurses who have used handheld devices for care planning improved patient-centered care and patient outcomes. ${ }^{[20]}$ Other nurses working in acute care hospitals, home care settings, longterm care facilities, and in primary care programs reported an improvement in their skills and awareness of research evidence when they accessed clinical information resources via mobile devices. Consequently, these nurses indicated that accessing information using their mobile devices assisted them in their clinical practice ${ }^{[21]}$ and improved the effectiveness and efficiency of patient care. ${ }^{[22]}$ Other researchers have found that registered nurses who use mobile devices spent

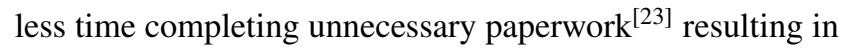
increased patient safety. ${ }^{[1,2,24,25]}$ 


\subsubsection{Mobile technologies and undergraduate nursing stu-} dents

In a systematic review of healthcare applications for smartphones, ${ }^{[26]}$ applications designed for educational purposes were reported to be a particularly good way to study especially in the absence of textbooks. Students are able to access necessary information independent of place and time. ${ }^{[27]}$ As a result, they have higher levels of self-efficacy ${ }^{[28]}$ making them feel more effective in the provision of nursing care. ${ }^{[2,29]}$ Indeed, since students do not have to leave their patients to access information, mobile devices are thought to encourage active learning by engaging students in information seeking activities. Theoretically, students are thereby supported in their provision of a safer, higher quality of patient care. ${ }^{[27,28]}$ However, vanVelsen et al. have found that the great number of health apps available for smartphones has created difficulty for healthcare professionals in finding the right app resulting in fragmentation of information and app overload.

Despite reports that the use of mobile devices support evidence-based practice and the complex thinking necessary for sound clinical decision-making, ${ }^{[28]}$ discussion in the literature regarding the advantages on mobile technology is largely descriptive and anecdotal. ${ }^{[31]}$ In a mixed-method descriptive pilot study, students and staff nurses reported positive results on the ability to make clinical decisions and improved confidence in patient care while using smartphones. ${ }^{[32]}$ On the other hand, in a comparative descriptive study ${ }^{[33]}$ that explored the use of mobile technologies to support clinical reasoning in senior undergraduate nursing students completing a 14-week clinical course which included students' questioning practices, propensity to seek answers to questions, and articulation of their rationale for interventions, Kuiper concluded that it was inappropriate to claim that personal digital assistant (PDA) resources reduced medication errors and healthcare costs, improved diagnostic reasoning, or promoted the development of effective treatment protocols. This is due to the absence of any statistically significant differences in clinical reasoning between PDA users and non-PDA users. Given the apparent conflicting evidence, further research is needed.

\subsection{Background}

The use of handheld technology in nursing curricula began about 20 years ago with the introduction of PDAs. ${ }^{[34]}$ The Canadian Association of Schools of Nursing (CASN), the national organization for undergraduate nursing education in Canada where this study took place, states that all newly graduated registered nurses should possess nursing informatics competencies so that they might be able to function efficiently, effectively, and safely in an increasingly technology- enabled practice environment. ${ }^{[35]}$ Thus, like our American counterparts, Canadian nursing programs have been encouraged to incorporate technology into nursing curricula. ${ }^{[36-38]}$ However, more than half of Canadian undergraduate nursing schools do not have a strategic plan or vision with goals and supportive policies for the integration of nursing informatics (NI) and information and communication technologies (ICT). This is a significant shortcoming, and one that may be responsible for the NI knowledge gap in new graduates. ${ }^{[38]}$ As a result, the use of mobile technologies is not only inconsistent across Canadian undergraduate nursing programs, but their impact on students' critical thinking and clinical decision making ability at the point of care is at best, unknown, and at its worst, totally absent.

There are thousands of medical, healthcare, and fitness smartphone apps available for download. ${ }^{[4]}$ That being said, some studies have found that nurses who use mobile devices at the point-of-care want access to reference sources and textbooks, drug reference information, intravenous compatibility guidelines, and institutional policies and procedures. ${ }^{[21,39]}$ Using the criterion of comprehensiveness and accessibility, we determined that the PEPID Professional Nurse Suite package offered the most comprehensive suite of resources in line with the purpose of this study. The suite includes clinical/medical information for over 2300 health conditions, nursing diagnoses, medication and intravenous compatibility, recently published research, laboratory and diagnostic information, and patient teaching information. Furthermore, because PEPID Professional Nurse Suite is a native app (an application that has been developed for use on a particular platform or device), access to the Internet while using it is not required. Thus, the students were able to turn their smartphone to 'airplane' mode while in the practice setting. This addressed concerns that the smartphone signal might interfere with medical equipment, and that students might access social media sites for non-professional purposes. Importantly, regular updates were available, and could be downloaded from personal home computers.

\subsubsection{Setting}

The undergraduate nursing program where this study was conducted is located in the province of Alberta, Canada. Data were collected from May 2013 to December 2014 during the senior preceptored clinical course. This clinical course is 350 hours in duration and takes place in a practice setting of the student's choosing under the supervision of a registered nurse preceptor. The participants in this study completed their preceptorship on medical, surgical, or critical care units (emergency or intensive care) in an urban tertiary hospital. 


\subsubsection{Ethics}

Ethics approval was obtained from the university's research ethics committee (Protocol \#2013-021). Participant rights were verbally explained during recruitment and prior to completing the first questionnaire. Patient confidentiality and infection control measures related to mobile phone use at the point of care as per institutional policy were explained. Recruitment was undertaken during orientation to the preceptorship course by the principal investigator and/or research assistant both of whom had no previous contact with the potential participants and no formal ongoing relationship. Study procedures were explained and questions answered at the outset of the study. Return of the completed questionnaires throughout the study implied consent and continued participation. To ensure confidentiality, each participant was assigned a code number. Only the principal investigator and research assistant had access to the list of participant names and codes. The questionnaires at the end of the preceptorship were returned to the research assistant via email. Once participant data were entered into a spreadsheet, the list linking participant names and code numbers was destroyed. Only after the data were anonymized did other members of the team have access to the data. Participants were compensated for their participation in the study by having access to the app free of charge for the duration of the preceptorship.

\section{MethodS}

\subsection{Design}

A pretest-posttest approach was used to answer the question: What is the effect of mobile technologies on undergraduate nursing students' perception of their ability to engage in critical thinking and clinical decision-making abilities at the point of care?

\section{Participants}

Fourth year undergraduate nursing students at the researchers' university who were completing their preceptorship were invited to participate in the study. A convenience sample of 30 students completed and returned the questionnaire. All participants were instructed to use the app as well as resources normally used during clinical courses: textbooks, policy and procedure manuals, research articles, and drug guides. Ninety six percent of participants reported feeling very comfortable using mobile technologies and in their ability to monitor and review their practice skills (mean = 3.77/5). Therefore, homogeneity was assumed.

\subsection{Data collection}

The questionnaires used to measure the critical thinking and clinical decision making ability of the participants were the Clinical Decision Making in Nursing Scale (CDMNS) ${ }^{[40]}$ and Clinical Effectiveness and Evidence Base Practice Questionnaire (EBPQ) ${ }^{[41]}$ Both of these questionnaires have been extensively used and supported the focus and aim of the proposed research study. Cronbach's alpha for the former was 0.83 and 0.87 for the latter. Both questionnaires used a 5 point Likert scale with responses ranging from never (1) to always (5). The CDMNS has 40-items and the EBPQ has 25 -items. The questionnaire was completed during the orientation to the preceptorship (T1) and at the end of the preceptorship (T2). To encourage students to complete and return the questionnaires, the research assistant sent reminder text messages and/or emails to the participants.

\subsection{Data analysis}

Data were analyzed using the Statistical Package for the Social Sciences (SPSS) v. 22. Descriptive statistics were calculated for all survey items. Paired samples T-test was used to test for differences within $\mathrm{T} 1$ and $\mathrm{T} 2$. Cronbach alpha was used to complete the reliability analysis of the questionnaire (CDMNS: .741; EBPQ: .806).

\section{RESULTS}

In short, there was no difference in students' overall perceived critical thinking ability over time (CDMNS: $p=.212$ ). However, there were some statistically significant differences between the participants' perception in their ability to engage in evidence-based practice (EBPQ) over time (see Table 1). This finding suggests that as participants use of the app increased over time, they believed it would consistently provide the answers they needed. Participants remained satisfied with the information the app was providing. Hence, they were less likely to question that information or to seek other sources of information such as institutional policies. As such, any disconfirming information was not in their purview.

Table 1. Clinical Effectiveness and Evidence Based Practice Questionnaire (EBPQ) T1, T2

\begin{tabular}{llll}
\hline Subscale Item & M (SD) & Test Statistic & $P$ \\
\hline $\begin{array}{l}\text { EBPQ14. How would you } \\
\text { rate your monitoring \& } \\
\text { reviewing of practice skills? }\end{array}$ & $3.53(.629)$ & -2.041 & .050 \\
$\begin{array}{l}\text { EBPQ18. How would you } \\
\text { rate your knowledge of how } \\
\text { to retrieve evidence? }\end{array}$ & $3.50(.682)$ & -2.504 & .018 \\
$\begin{array}{l}\text { EBPQ 20. How would you } \\
\text { rate your ability to determine }\end{array}$ & $3.07(.583)$ & -3.791 & .001 \\
$\begin{array}{l}\text { how (close to the truth) the } \\
\text { material is? }\end{array}$ & $3.50(.731)$ & & \\
$\begin{array}{l}\text { EBPQ 21. How would you } \\
\text { rate your ability to determine } \\
\text { how useful (clinically } \\
\text { applicable) the material is? }\end{array}$ & $3.23(.728)$ & & .014 \\
\hline
\end{tabular}

Note. ${ }^{*} p<.05 ;{ }^{* *} p<.01 . \mathrm{M}=$ Mean; $\mathrm{SD}=$ Standard Deviation 


\section{Discussion}

In keeping with Kuiper's ${ }^{[33]}$ and Gorelick ${ }^{[31]}$ conclusions, the findings of this study suggest that the use of a clinical mobile app did not significantly influence undergraduate nursing students' perceived ability to think critically while engaged in decision-making. It is plausible that the participants may not have considered the patient's context demonstrating a lack of context-sensitivity. ${ }^{[42]}$ As well, the participants may have oversimplified their thinking, failing to look beyond the obvious. This can lead to overgeneralizing pieces of information, and uncritically engaging in either-or thinking that ignores the possibility of multiple answers to common questions. It is important to note however, that the participants anecdotally reported that they were frequently asked by nursing staff to retrieve information which allowed them to establish positive rapport with the staff. Relationships with staff members are a factor that positively affects students' ability to learn and engage in clinical decision-making and better understanding of the clinical picture. ${ }^{[43]}$ This may be due to the increasing value placed upon collaborative thinking within the decision-making process.

Contrary to the findings of other studies where multiple sources of information were viewed as desirable, ${ }^{[21,39]}$ the students in this study seemed to be satisfied with using the app as their only major source of information. Consequently, they may not have felt the need to expand their search for information beyond the app itself. Accordingly, other important pieces of information such as institutional policies and procedures were not consulted. This is deeply significant. Making clinical decisions without thinking critically about the reliability of all relevant sources of information can seriously jeopardize patient safety. On the other hand, like other studies, ${ }^{[29,44]}$ these student may have perceived that their ability to engage in evidence-based practice was enhanced due to their success in information retrieval.

\subsection{Implications}

Intuitively, the use of mobile technologies seems like an appropriate practice for health care professionals. Mobile technologies themselves can be an important resource for clinical practice because of their accessibility. As well, their use is consistent with the notion that clinical decision support is a core function of health information systems. ${ }^{[5]}$ Given the results of this study, however, nurse educators must teach students to think critically about the information accessed through those mobile technologies. Nurse educators need to encourage students to be active learners who value thinking critically about the relevance of the information available through the app when making decisions about patient care. In short, nursing educators need to nurture a sensitivity to context that prevents students from becoming overly dependent on the app itself. ${ }^{[46]}$ This is more likely to occur if, nursing students are encouraged to use their critical thinking skills while accessing information on the app. Notably such a requirement attends to the kind of critical thinking nurses need to regularly demonstrate on a shift.

To this end, nurse educators need to infuse critical thinking into their daily, ongoing instructional contexts in order to make the best decisions possible. Such a focus will not only help nursing students develop their critical thinking skills but nurture a spirit of critical inquiry as well. For example, nurse educators can role model the proper use of critical thinking through the think-aloud method. ${ }^{[47,48]}$ Moreover, students need to understand that although apps like the one used in this study are comprehensive, key information sources like institutional policies and procedures are not included in them. This means that students need to see how nurses actually utilize information from many sources in resolving identified problems. Importantly and in support of Sullivan's ${ }^{[46]}$ recommendation, students in all levels of a nursing program need to observe what nurses are doing when they are thinking critically. That is, they are asking probing questions, identifying and questioning assumptions and inferences, seeking out multiple perspectives, incorporating diverse points of view, and being context-sensitive in their decision making.

\subsection{Limitations}

As is the case with all research, the findings of this study should be interpreted within the context of its limitations. This was a cross-sectional study of students in one program with a relatively small sample size. Since mobile device studies usually have a small number of participants due to high costs for hardware and software, ${ }^{[27]}$ generalizability of the findings to other undergraduate nursing students is limited. Self-report is also notoriously problematic as it is subjective and may not be entirely representative of respondents' abilities. Therefore, it is possible that the participants conflated their ability and competence in critical thinking and clinical decision making in their self-report. ${ }^{[49,50]}$ Longitudinal studies from the first year to the end of the program would enhance our knowledge of how mobile technologies support students' critical thinking and clinical decision making abilities.

\section{Conclusion}

The use of mobile technologies including applications has become widely popular among nurses and nursing students. These technologies are assuming an increasingly prominent position in healthcare settings. In order to protect the public and provide safe, effective and efficient nursing care, 
however, students need to recognize the value of thinking critically when using these technologies to make sound decisions. They need to see critical thinking as the basis for their clinical decision-making. Hence, nurse educators need to be knowledgeable of a variety of critical thinking skills, strategies and attitudes. This background knowledge has the potential to promote a deeper professionalism in nursing education, holding nursing students accountable in the decisions they make when using mobile technologies.

Health care will continue to expect nurses to solve more complex problems, make better decisions, and be more in- novative problem-solvers and problem-posers. Our role as nurse educators is to ensure our students have the requisite critical thinking skills and attitudes necessary for the provision of high-quality evidence based care. Whether it is using mobile technologies on a shift or listening to patients at their bedside, a nurse who can think critically about what to do next, is more likely to make good decisions in a variety of nursing contexts.

\section{CONFLICTS OF INTEREST DisClOSURE}

The authors declare that there is no conflict of interest.

\section{REFERENCES}

[1] Honeybourne C, Sutton S, Ward L. Knowledge in the palm of your hands: PDAs in the clinical setting. Health Information and Libraries Journal. 2006; 23: 51-59. PMid:16466499. http://dx. doi.org/1 $0.1111 / j .1471-1842.2006 .00621 . x$

[2] Hudson K, Buell V. Empowering a safer practice: PDAs are integral tools for nursing and health care. Journal of Nursing Management. 2011; 19: 400-406. PMid:21507112. http://dx.doi .org/10.11 $11 / j .1365-2834.2011 .01251 . x$

[3] Chatterley T, Chojecki D. Personal digital assistant usage among undergraduate medical students: Exploring trends, barriers, and the advent of smartphones. Journal of the Medical Library Association, 2010; 98: 157-160. PMid:20428281. http://dx.doi.org/10.31 $63 / 1536-5050.98 .2 .008$

[4] Koehler N, Vujovic O, McMenamin C. Healthcare professionals' use of mobile phones and the Internet in clinical practice. Journal MTM 2013; 2: 3-13. http://dx.doi.org/10.7309/jmtm. 76

[5] Stroud SD, Smith CA, Erkel EA. Personal digital assistant use by nurse practitioners: A descriptive study. Journal of the American Academy of Nurse Practitioners. 2009; 21: 31-38. PMid:19125893. http://dx.doi.org/10.1111/j.1745-7599.2008.00368.x

[6] Mosa ASM, Yoo I, Sheets L. A systematic review of healthcare applications for smartphones. BMC Medical Informatics and Decision Making. 2012; 12: 67. Available from: http://www. biomedcentral. com/1472-6947/12/67 PMid:22781312. http: //dx.doi.org/10.1186/1472-6947-12-67

[7] Lasater K. Clinical judgment: The last frontier for evaluation. Nursing Education in Practice. 2011; 11: 86-92. PMid:21212021. http://dx.doi.org/10.1016/j.nepr.2010.11.013

[8] College \& Association of Registered Nurses of Alberta. Entry-topractice competencies for the registered nurses profession. Edmonton, AB: College and Association of Registered Nurses. 2013. Available from: www.nurses.ab.ca

[9] Tanner CA. What have we learned about critical thinking in nursing? Journal of Nursing Education. 2005; 44(2): 47-48. PMid:15719709.

[10] Allen GD, Rubenfeld MG, Scheffer BK. Reliability of assessment of critical thinking. Journal of Professional Nursing. 2004; 20(1): 111-119.

[11] Chan ZCY. A systematic review of critical thinking in nursing education. Nurse Education Today. 2013; 33: 236-240. http:// dx.doi.org/10.1016/j.nedt.2013.01.007. PMid:23394977. http://dx.doi.org/10.1016/j.nedt.2013.01.007

[12] Etheridge SA. Learning to think like a nurse: Stories from new nurse graduates. Journal of Continuing Education in Nursing. 2007;
38(1): 24-30. http://dx.doi.org/10.3928/00220124-20070 101-05

[13] Finn P. Critical thinking: Knowledge and skills for evidence-based practice. Language, Speech, and Hearing Services in Schools. 2011; 42: 69-72. http://dx.doi.org/10.1044/0161-1461 (2010/0 9-0037)

[14] Simmons B. Clinical reasoning: Concept analysis. Journal of Advanced Nursing. 2010; 66(5): 1151-1158. PMid:20337790. http: //dx.doi.org/10.1111/j.1365-2648.2010.05262.x

[15] Bowles K. The relationship of critical-thinking skills and the clinical judgment skills of baccalaureate nursing students. Journal of Nursing Education. 2000; 39(8): 373-376. PMid:11103976.

[16] Profetto-McGrath J. Critical thinking and evidence-based practice. Journal of Professional Nursing. 2005; 21(6): 364371. PMid:16311232. http://dx.doi.org/10.1016/j.profn urs.2005.10.002

[17] Brian J, Brian D, Hildebrandt S, et al. Software for nursing: RNs are mobilizing. New York, NY: Springer; 2004. 289 p.

[18] Broussard B, Broussard A. Using electronic communication safely in health care settings. Nursing for Women's Health. 2013; 17: 59-62. PMid:23399014. http://dx. doi .org/10.1111/1751-486X.12 007

[19] Wyatt TH, Krasukopf PB, Gaylord NM, et al. Cooperative m-learning with nurse practitioner students. Nursing Education Perspectives. 2010; 31(2): 109-113. PMid:20455369.

[20] Ruland CM. Handheld technology to improve patient care: Evaluating a support system for preference-based care planning at the bedside. Journal of the American Medical Informatics Association. 2002; 9(2): 192-201. http://dx.doi.org/10.1197/jamia.M0891

[21] Doran DM, Haynes RB, Kushniruk A, et al. Supporting evidencebased practice for nurses through information technologies. Worldviews on Evidence-Based Nursing. First Quarter 2010; 7(1): 4-15. PMid:20028493. http://dx.doi.org/10.1111/j.1741-6787. 2009.00179.x

[22] Qadri SS, Wang Ruiz JG, Roos BA. Personal digital assistants as point-of-care tools in long-term care facilities: A pilot study. Educational Gerontology. 2009; 35: 294-305.

[23] Hong HS, Kim IK, Lee SH, Kim HS. Adoption of a PDA-based home hospice care system for cancer patients. CIN: Computers, Informatics, Nursing. 2009; 27(6): 365-371.

[24] Johansson P, Petersson G, Saveman B, et al. Using advanced mobile devices in nursing practice - the views of nurses and nursing students. Health Informatics Journal. 2014; 20(3): 220-231. Avail- 
able from: http://jhi.sagepub.com PMid:25183609. http: //dx.doi.org/10.1177/1460458213491512

[25] Johansson P, Petersson G, Saveman B, et al. Experience of mobile devices in nursing practice. Nordic Journal of Nursing Research \& Clinical Studies. 2012; 32(4): 50-54. http://dx.doi.org/10.11 $77 / 010740831203200411$

[26] Mosa ASM, Yoo I, Sheets L. A systematic review of healthcare applications for smartphones. BMC Medical Informatics and Decision Making. 2012; 12: 67. PMid:22781312. http://dx.doi.org/10. 1186/1472-6947-12-67

[27] Johansson PE, Petersson GI, Nilsson GC. Nursing students' experience of using a personal digital assistant (PDA) in clinical practice - an intervention study. Nurse Education Today. 2013; 33(10): 1246-1251. PMid:22999410. http://dx.doi.org/10.1016/j.n edt. 2012.08.019

[28] Goldsworthy S, Lawrence N, Goodman W. The use of personal digital assistants at the point of care in an undergraduate nursing program. CIN: Computers, Informatics, Nursing. 2006; 24(3): 138-143.

[29] Pattilo RE, Brewer M, Smith C. Tracking clinical use of personal digital assistant reference resources. Nurse Educator. 2007; 32(1): 39-42. http://dx.doi.org/10.1097/00006223-200701000-00011

[30] vanVelsen L, Beaujean DJMA, vanGemert-Pijnen JEWC. Why mobile health app overload drives us crazy, and how to restore the sanity. BMC Medical Informatics and Decision Making. 2013; 13: 23. PMid:23399513. http://dx.doi.org/10.1186/1472-694 7-13-23

[31] Gorelick CS. Personal digital assistants: Their influence on clinical decision-making and the utilization of evidence-based practice in baccalaureate nursing students. Unpublished dissertation 2010. Duquesne University, Pittsburgh, PA.

[32] Wittmann-Price RA, Kennedy LD, Godwin C. Use of personal phones by senior nursing students to access health care information during clinical education: Staff nurses' and students' perceptions. Journal of Nursing Education. 2012; 51(11): 642-646. PMid:22978275. http://dx.doi.org/10.3928/01484834-201 20914-04

[33] Kuiper R. Use of personal digital assistants to support clinical reasoning in undergraduate baccalaureate nursing students. CIN: Computers, Informatics, Nursing. 2008; 26(2): 90-98.

[34] Koeniger-Donohue R. Handheld computers in nursing education: A PDA pilot project. Journal of Nursing Education. 2008; 47(2): 74-77. http://dx.doi.org/10.3928/01484834-20080201-01

[35] Canadian Association of Schools of Nursing. Nursing Informatics Entry-to-Practice Competencies for Registered Nurses. Ottawa, ON: Canadian Association of Schools of Nursing; 2012. Available from: www. casn.ca

[36] American Association of Colleges of Nursing. The essentials of baccalaureate education for professional nursing practice 2008. Available from: http://www . aacn.nche.edu/education-resources/B accEssentials08.pdf

[37] National League for Nursing NLN research priorities in nursing education 2012-2015. 2012. Available from: http://www.nln.org/ researchgrants/researchpriorities.pdf

[38] Pilarski T. Where is nursing informatics in undergraduate nursing education? CJNI: Canadian Journal of Nursing Informatics. 2010; 5(4): Article Two. Available from: http://cjni.net/journal/? $\mathrm{p}=1041$

[39] Royle JA, Blythe J, DiCenso A, et al. Evaluation of a system for providing information resources to nurses. Health Informatics Journal. 2000; 5: 100-109. http://dx.doi.org/10.1177/14604582000 0600208

[40] Jenkins HM. Clinical decision making in nursing scale. New York, NY: Springer; 2001. 33 p.

[41] Upton DR, Upton PM. Development of an evidence-based practice questionnaire for nurses. Journal of Advanced Nursing. 2006; 54(4): 454-458.

[42] Kida T. Don't believe everything you think: The 6 basic mistakes we make in thinking. Amherst, NY: Prometheus; 2006.

[43] Levett-Jones T, Lathlean J, Higgins I, et al. Staff-student relationships and their impact on nursing students' belongingness and learning. Journal of Advanced Nursing. 2009: 316-324.

[44] Baudloff G, Kirkpatrick B, Sheets D, et al. Implementation of handheld devices. Nurse Educator. 2008; 33(6): 244-248. PMid:18981902. http://dx.doi.org/10.1097/01. NNE.0000 334788.22675.fd

[45] Cho I, Kim J, Kim J, et al. Design and implementation of a standardsbased interoperable clinical decision support architecture in the context of the Korean EHR. International Journal of Medical Informatics. 2010; 79(9): 611-622. PMid:20620098. http://dx.doi.org/10. 1016/j.ijmedinf .2010.06.002

[46] Sullivan EA. Critical thinking in clinical nurse education: Application of Paul's model of critical thinking. Nurse Education in Practice. 2012; 12: 322-327. PMid:22525831. http://dx.doi.org/10.10 $16 / j$.nepr.2012.03.005

[47] Gardin F. The "think-aloud" method to promote student modeling of expert thinking. Athletic Therapy Today. 2010; 15(4): 18-21.

[48] Paul R, Elder L. Critical thinking competency standards. Dillon Beach, CA: The Foundation for Critical Thinking Press; 2007.

[49] Eva KW, Regehr G, Gruppen L. Blinded by "insight": Selfassessment and its role in performance improvement. New York: Cornell University Press; 2011. 131 p.

[50] Kruger J, Dunning D. Unskilled and unaware of it: How difficulties in recognizing one's own imcompetence lead to inflated selfassessments. Journal of Personality \& Social Psychology. 1999; 77(6): 1121. http://dx.doi.org/10.1037/0022-3514.77.6 .1121 